\title{
MANAGING EMERGENCY INTO HISTORIC CENTRES IN ITALY: SEISMIC VULNERABILITY EVALUATION AT URBAN SCALE
}

\author{
Francesca Giuliani ${ }^{1}$, Anna De Falco ${ }^{1}$, Giacomo Sevieri ${ }^{2}$, Valerio Cutini ${ }^{1}$ \\ ${ }^{1}$ Department of Energy, Systems, Territory and Construction Engineering, University of Pisa \\ Largo Lucio Lazzarino \\ e-mail: francesca.giuliani@ing.unipi.it, a.defalco@ing.unipi.it, valerio.cutini@ing.unipi.it \\ ${ }^{2}$ Department of Civil and Industrial Engineering, University of Pisa \\ Largo Lucio Lazzarino \\ giacomo.sevieri@unifi.it
}

\begin{abstract}
Italy is one of the most earthquake prone areas in Europe and one of the countries with the richest cultural legacy in the world. A series of seismic events occurred in the last decades caused considerable casualties and damage to historic centres, highlighting the need of undertaking protective measures to limit the impact of any potential earthquake. The complex morphology of historical city centres with their century-old built environment contribute to the high vulnerability and exposure in the areas. This research introduces an interdisciplinary approach to implement the seismic emergency management for historical centres in Italy and consequently to address their preventive planning.

A procedure combining vulnerability analysis and urban spatial techniques allows defining a ranking of priority interventions to be included into a preventive plan in order to ensure free escape routes and clear access for the emergency services during the post-seismic phase. The first step of this work is the survey of the present-day configuration of historic centres, with their historical assets, aggregates, critical infrastructures, urban functions and strategic activities. Then, a key aspect regards the vulnerability assessment of the urban fabric in order to predict post-seismic damage scenarios. By considering the interference of the buildings' vulnerability with the street network, it is possible to develop mitigation strategies to improve the emergency management.
\end{abstract}

Keywords: Historical centres, configurational analysis, seismic vulnerability, emergency management 


\section{INTRODUCTION}

The last decades have witnessed a growing awareness of the necessity to reduce disaster risk in urban areas by adopting a wider perspective, not only focused on the single building but on the urban and territorial system as a whole. In fact, urban centres are complex systems that can't be simplistically reduced to units; their management, especially in case of disaster risk reduction, requires an integrated approach that takes into account natural and man-made hazards [1]. According to this vision, the UN's Sendai Framework for Disaster Risk Reduction [2] encourages the integration of risk management strategies into the urban agendas in order to improve and foster the resilience of the built environment. Therefore, efforts should aim to link the risk assessment to the management phase, especially in case of seismic risk. When dealing with earthquakes, it is impossible to avoid the hazard or predict the occurrence of a shock. Therefore, risk can be mitigated only by reducing vulnerability and exposure.

Italy is an earthquake-prone country that falls in one of the most seismically active areas in Europe. It has faced several earthquakes of high magnitude that had a greater impact on the built environment, and particularly on historic centres (e.g. 2009 L'Aquila, 2016 Amatrice). Thanks to their distinct morphology, urban fabric and architecture, historic centres are today both cultural resources and fragile areas. In fact, the characteristics of the built environment and of the current way of living contribute to increase the vulnerability and exposure in the site. On the one hand, vulnerability is affected by the great and diffuse presence of historic buildings and by the morphological evolution of the urban structure resulting from a centuries-old process of aggregation, space saturation and adaptation to the territory. Factors that contribute to the higher liability to collapse are related to a series of practices processed over generations, such as unmanaged stratifications, change of use in buildings and aggregates, lack of maintenance, mixed construction types with a misuse of modern constructive materials on vernacular architecture. Italian historic centres are characterized by a great presence of unreinforced masonry buildings, each one having a specific structural evolution that hinders the confident survey of the extent and quality of components and materials. From an urban perspective, further vulnerabilities are the presence of narrow, winding streets and the lack of open spaces. On the other hand, historic settlements present an elderly resident population and a high concentration of tourists that can be exposed to risk.

During the last decades, the safety of historic centres has been largely investigated from different perspectives, through methodologies pertaining to different disciplines - seismic engineering, risk management, urban planning - and at different scales - national, territorial, urban, building. Despite the large number of studies conducted during the past years, only a limited number of researches has attempted to combine seismic engineering with risk management and urban planning $[3,4,5]$.

In this study, the main objective is to improve the emergency response of the urban system in Italian historic centres. Soon after an earthquake, the most important aspects are the autonomous evacuation of people along safe routes, the prompt operability of strategic functions and the access of emergency services. So that the emergency response is more effective if a number of routes are safe and free from debris or fallen obstacles. These emergency routes should be preventively identified considering accessibility and damage scenarios. In this study, accessibility scenarios are based on the location of strategic functions and on the results of the configurational analysis of the historical settlements. Instead, damage scenarios depend on the urban vulnerability assessment conducted through empirical methods. The main output of the analysis are the evaluation of both the importance of a street for the emergency management and its liability to be blocked, due to the presence of vulnerable buildings along the route. By overlapping these aspects, it is possible to identify actions to reduce the buildings' damage 
along the emergency routes, improving the overall resilience of the settlement and providing a prioritization criterion in planning preventive actions [6]. The accessibility and damage scenarios have been assessed for a case study in Tuscany, the historic centre of Lucignano.

\section{THE EMERGENCY MANAGEMENT: ACCESSIBILITY AND DAMAGE SCENARIOS}

\subsection{The accessibility scenarios}

The current National Seismic Prevention Programme, promoted by the Italian Department of Civil Protection (DCP), is conducting microzonation studies and interventions for seismic retrofitting of strategic buildings, as well as funding private initiatives for local strengthening of properties [7]. Besides, the DCP adopted the Limit Condition for Emergency (LCE) [8] introducing a planning concept derived from Performance Based Seismic Design. The approach developed from the Augustus Method that has been the major reference for emergency management in Italy overtime [9]. The LCE is based on the Urban Limit States and identifies four damage scenarios in which the urban functions are gradually interrupted. Assuming that the urban vulnerability can involve different sub-systems by affecting their functionality, the LCE introduces performance levels at the urban scale. With reference to emergency, the Emergency Limit State entails the loss of most of the urban functions except for the strategic functions for the emergency management. It corresponds to a worst-case scenario in which only the strategic functions, their internal connection and the access routes from the territorial context are preserved. The main problem in the application of the LCE concept, which is based on a functional approach only, is that it is not suitable as a planning tool for historic centres where safety strongly depends on the vulnerability of buildings.

A further issue concerns the prediction of the evacuation of people during the emergency which is commonly neglected even though the safeguarding of human life is of upmost importance in risk management. In this situation, approaches based only on the calculation of geometrical distances can't be representative of the way people use the space. Human behaviour indeed is strongly guided by space perception and previous experience.

This study is based on the combination of accessibility scenario and damage scenario on the basis of specific indices. According to the LCE, the accessibility scenario considers the strategic functions and the emergency areas located within the boundaries of the historic centres, such as operative centres, town hall, hospitals, schools, and open spaces [10]. The scenario includes also the routes for emergency services, connecting these areas and strategic functions. Another key aspect in the accessibility scenario is the evacuation of people. This can be described through space syntax analysis, that is a configurational approach based on a topological description of the open spaces in the urban centre. According to the theory [11, 12], the urban grid has a primary role in urban dynamics with a strong relationship between the topology of the network and the distribution of 'natural movement' $[13,14]$. In recent years, space syntax research has focused on disaster risk management $[15,16,17]$ due to its capacity to describe the 'wayfinding behaviour' [18] through spatial indicators. In this paper, the analysis has been applied to address the efficient route-finding decision making in case of earthquake. In fact, it allows selecting the sensitive paths, corresponding to the ones that could be critical due to the presence of great flows. The term 'sensitive' refer to those streets that are likely to be chosen as evacuation routes from residents or visitors to escape from the historic centres. The most suitable spatial indicator for this application is the choice index $\left(\mathrm{I}_{\mathrm{ch}}\right)$. It is calculated by counting the number of times each street segment falls on the shortest path between all pairs of segments within a selected distance. The 'shortest path' refers to the path of least angular deviation (namely, the straightest route) through the system [19]. The combi- 
nation of the data from the LCE and the spatial analysis provides the accessibility scenario during the emergency.

\subsection{The damage scenarios}

The estimation of damage during a seismic event is a challenging task because of the large number of buildings - most of them are URM structures - and the lack of information, especially on historical buildings. According to Dolce et al. [20], the construction of damage scenarios to buildings consists of three main steps: the preliminary typological analysis and the collection of information on the building stock (geometrical-qualitative characteristics and/or mechanical-quantitative characteristics of the buildings); the seismic vulnerability assessment; and the definition of the characteristics of ground shaking, including possible site effects. Seismic vulnerability of buildings can be assessed through different methods having different levels or accuracy $[21,22,23]$. For instance, analytical methods are based on structural analyses to assess the seismic capacity of the buildings. Empirical methods, instead, are based on the definition of damage probability matrices or vulnerability functions from in-situ observation of the seismic damage after past major earthquakes. The latter are commonly adopted in large scale urban assessments.

In this study, the vulnerability has been evaluated with simplified methods on the basis of a uniform level of knowledge of the built environment. In particular, the vulnerability is derived from the application of the Vulnerability Index Method (VIM) for masonry facades [24, 25, $26]$ that allows evaluating the mean damage grade $\left(\mu_{\mathrm{d}}\right)$. The method can be applied to investigate the influence of the collapse of interfering buildings on the operation of emergency routes.

\section{VULNERABILITY ASSESSMENT IN HISTORIC CENTRES}

In the past years, several analysis methods have been developed to evaluate urban vulnerability with different simplifications in compliance with the necessary adoption of a wider - or holistic - perspective [21]. In fact, analytical tools for masonry buildings in aggregates have shown some limits [28, 29] for several reasons: a model of the single unit would neglect the so-called 'aggregate effect', namely the vulnerabilities induced by the interactions between adjacent units; while the urban scale requires processing huge amount of data and taking into account uncertainties related to the knowledge and the modelling of all the aggregates.

Nowadays, the assessment of urban vulnerability entails methods based on statistical data and damage observations of past seismic events. Several methodologies, classified as 'indirect', combine the vulnerability index method by Benedetti and Petrini [30] with the European Macroseismic Scale definition (EMS-98) by Grünthal et al. [31]

Among the several methodologies for a rapid vulnerability assessment, this study applies the VIM for masonry façades $[24,25,26]$ in compliance with the objective of the work. In fact, it allows identifying the interfering buildings whose damage or collapse may affect the functionality of the road network during the post-event emergency. The vulnerability index $\mathrm{I}_{\mathrm{vf}}$ for façade walls is based on 4 classes $C_{v i}$ of increasing vulnerability expressed by A, B, C, and D. The authors proposed a first index obtained as the weighted sum of the 13 parameters [24], which was later reviewed after a calibration study $[25,26]$. This paper adopts the second version of the VIM [25], in which the 13 parameters are combined through equation (1).

$$
I_{v f}=\sum_{i=1}^{13} C_{v i} p_{i}
$$


where $p_{i}$ are the weight factors assigned for each parameter.

Starting from the vulnerability index $I_{v f}$, the mean damage grade $\mu_{\mathrm{d}}$ is estimated through equation (2) [25]

$$
\mu_{d}=2,51+2,5 \times \tanh \left(\frac{I+5,25 \times V-11,6}{Q}\right)
$$

where $I$ is the seismic hazard in terms of macroseismic intensity scale EMS-98, $Q$ is a ductility factor for the structural typology and $V$ is the vulnerability evaluated with equation (3).

$$
V=0,592+0,0057 \times I_{v f}
$$

\section{THE COMBINATION OF SCENARIOS}

The concept of vulnerability, in the field of structural reliability, is defined as the susceptibility to damage of a given construction within a particular return period. In the context of this work, the vulnerability of a street is assumed as its susceptibility to be blocked by the collapse of the façades of the constructions on the roadside. In the context of people evacuation, the space syntax allows one to define a street network within the settlement. A value of vulnerability index can be assigned to each $i$-th segment of the street network, by assuming it as the maximum value of the mean damage grade $\mu_{d, \mathrm{i}}$ associated to the buildings on the roadside.

The novelty of this work lies in the definition of a procedure which allows one to combine the index deduced from the space syntax, the vulnerability of the street segment and its strategic function. This can be done in two steps. Firstly, the normalized "choice" indices $I_{C h, I}^{*}$ obtained as result of the space syntax analysis, are modified in order to consider the strategic function of the street segment, by following the condition (4)

$$
\mathrm{I}_{\mathrm{Ch}, i}^{*}= \begin{cases}1 & \text { if the segment is strategic } \\ \mathrm{I}_{\mathrm{Ch}, i} & \text { otherwise }\end{cases}
$$

Secondly, the mean damage grade $\mu_{d, \text { i i }}$ is multiplied by the modified normalized choice index $I^{*} C h, i$. In this way, the final streets' vulnerability index $I_{s, i}^{*}$ accounts also for the importance of the segment during the emergency within the historic centre.

\section{THE CASE STUDY}

The historic centre of Lucignano is in Tuscany and its territory is classified as seismic area graded with 3 , having a maximum PGA of $0.15 \mathrm{~g}$. Lucignano has a configuration arranged in elliptic shape with concentric rings of narrow streets, whose layout follows the orography of the terrain. Several radial roads link the outer ring to the top of the hill, where the public functions are located. It presents four accesses, three of them coincide with the historic gates, while the north-east passage has been realised with the demolition of a portion of the city walls. The perimeter of the historic centre is clearly visible even though the city walls have been progressively incorporated into private houses and historical buildings. Most of the historic centre is characterized by concentric aggregates composed by load-bearing unreinforced masonry buildings, with a prevalent linear articulation of the structural units and a clear structural continuity. 
Firstly, the characteristics of the entire building stock in the historic centre have been analysed. The vulnerability evaluation starts from the classification of the uses and characteristics of buildings, according to the Structural Plan of the Municipality, the ISTAT statistical data (year 2011) and on-site surveys. Among the geometrical and qualitative characteristics, the following data have been collected for each of the 248 buildings within the historic centre: height, plan and elevation configuration of the aggregates, age of construction, structural material, state of preservation, etc. Table 2 shows the distribution of the uses in term of number of buildings and percentage distribution. Most of the buildings are private property and about the $87 \%$ of them are dwellings. Only a small percentage of the building stock is public (regional, municipal or church properties), and it comprises administrative offices, schools, churches and healthcare services. The statistical data show that all the buildings, both private and public, are unreinforced masonry buildings, and this information is corroborated by the surveys. Besides the $87 \%$ of them was constructed before 1919 . However, no information is available on possible retrofitting interventions in reinforced concrete. The distribution of the number of stories presented in figure 2 highlights that almost the $95 \%$ of the masonry buildings have less than 3 stories.

Table 1 Historic centre of Lucignano: present-day distribution of buildings according to their use

\begin{tabular}{lll}
\cline { 2 - 3 } & Number & Distribution [\%] \\
\hline Total number of buildings & 248 & 100.00 \\
Building with a function & 246 & 99.19 \\
Residential buildings & 215 & 86.69 \\
Productive buildings & 14 & 5.65 \\
Public buildings & 17 & 6.85 \\
\hline
\end{tabular}
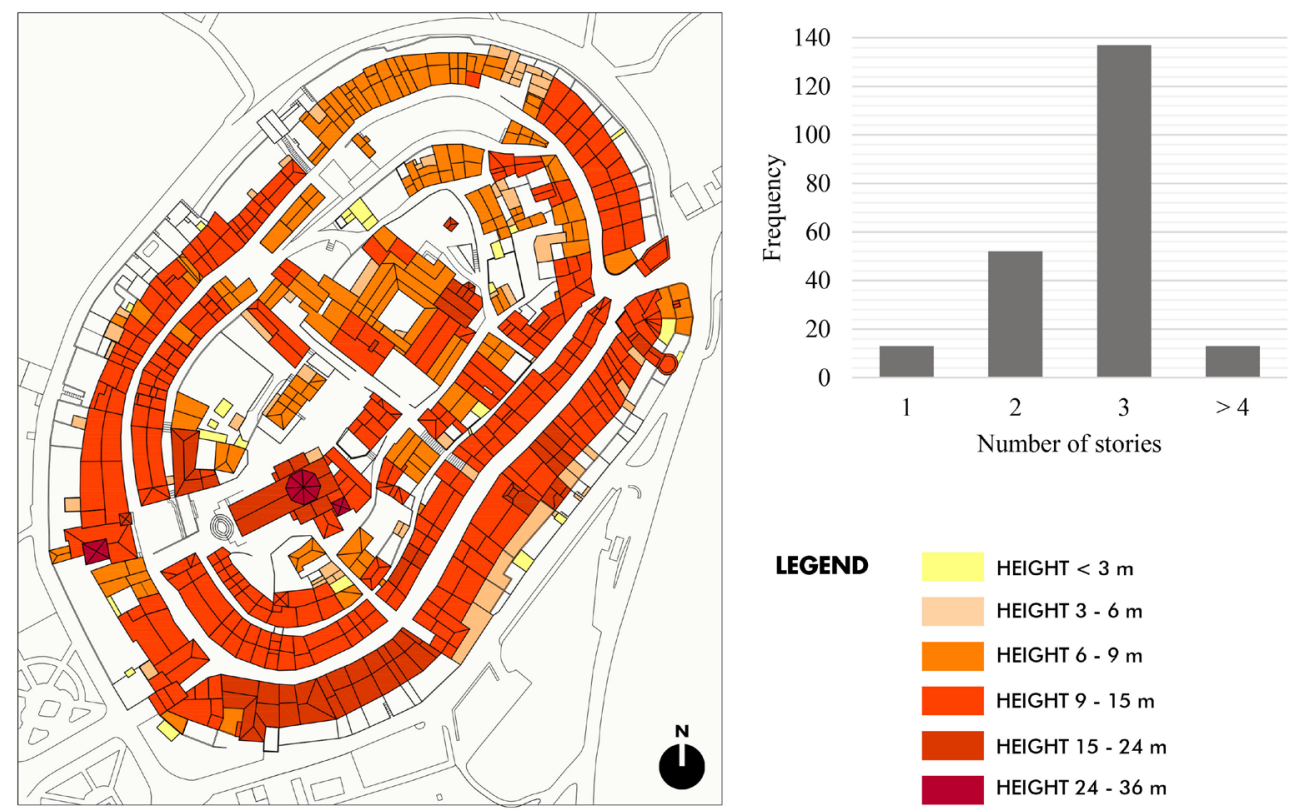

Figure 1 Map of the heights of the buildings in Lucignano and distribution of buildings according to the number of stories.

Several emergency services are located within the boundaries of the historic centre (figure 3). The town hall (TH) is hosted in an ancient building and it is part of an aggregate that includes the Church of San Francesco, which is listed as heritage according to National Protec- 
tion laws, and a primary and secondary school $(\mathrm{S})$. Other strategic uses for the emergency management are the police $(\mathrm{P})$ and healthcare $(\mathrm{H})$ functions, both located into the historic centre of Lucignano. The squares and the open spaces are identified as temporary emergency areas and meeting points to gather the population.
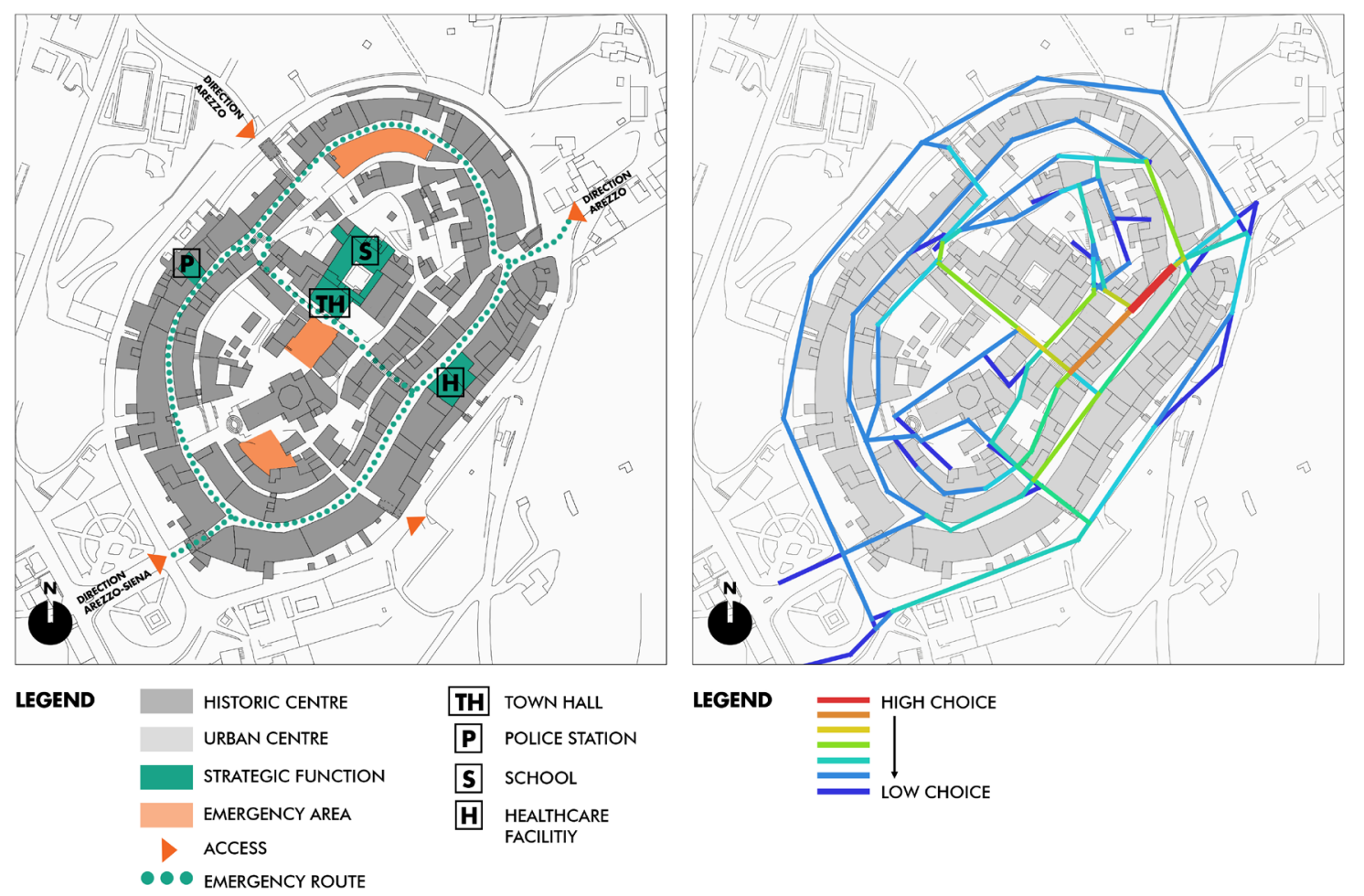

Figure 2 Historic centre of Lucignano. On the left, map of the strategic functions and emergency areas according to the LCE; on the right, gradient map of the evacuation routes according to the spatial analysis.

With reference to the selection of evacuation routes, the historic centre has been studied with the Angular Segment Analysis provided by the UCL Depthmap, which provides a total number of 158 segments. The paths with the highest choice values $\left(I_{c h, i}\right)$ are indicated in red and correspond to the ones that people tend to follow while moving into the town (figure 2). The results show that these routes differ from the LCE emergency routes, demonstrating that an approach only focused on the connection of emergency areas and services is not sufficient nor representative of the behaviour of people. In fact, if the routes are selected only considering the strategic functions, some relevant paths are neglected.

According to LCE, the geometrical approach provides the streets that should remain free, or partially free, from debris in case of collapse of the nearby buildings. The results (figure 4) show that, following the geometrical approach, most of the streets in Lucignano would be blocked, and only the $21 \%$ would allow emergency services to access the areas. Besides, the percentage is reduced to $6 \%$ if we exclude the outer circular road ring (composed by a number of 23 segments), considering the paths inside the settlements. The average width of the streets in the centre is $5,80 \mathrm{~m}$, while the $94 \%$ of the buildings has more than two stories (figure 2 ). This calculation can be a rapid screening tool to visualize if buildings interfere with the road network, however it doesn't provide a classification criterion.

As stated by the DPC, more than $25 \%$ of the casualties during earthquakes are caused by the collapse of non-structural elements, hence it is important to survey these elements on each building. In particular, the mapped non-structural deficiencies that can potentially cause road 
obstruction are infilled panels, chimneys, cantilevers, cornices and other heavy elements on facades (figure 3).

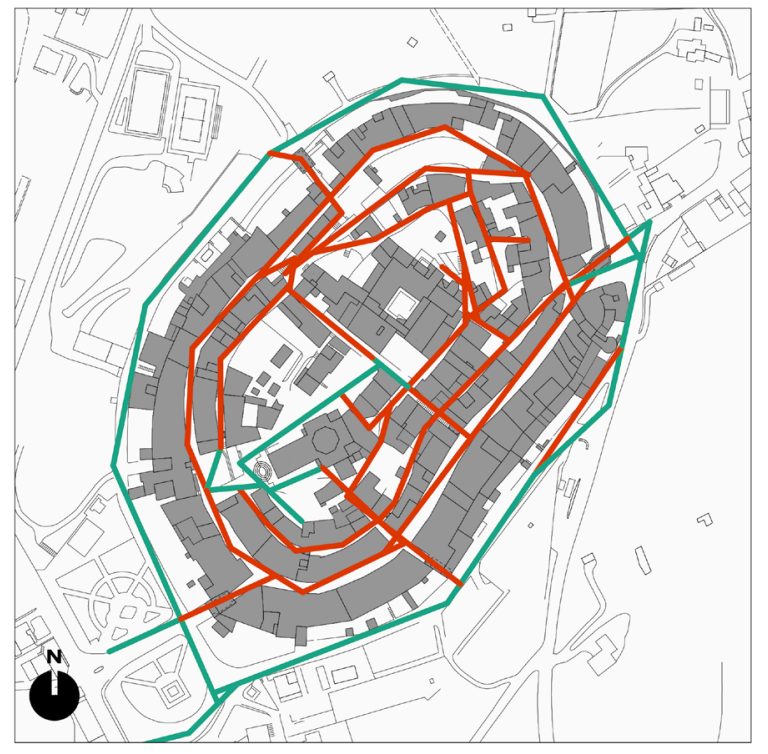

LEGEND

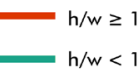

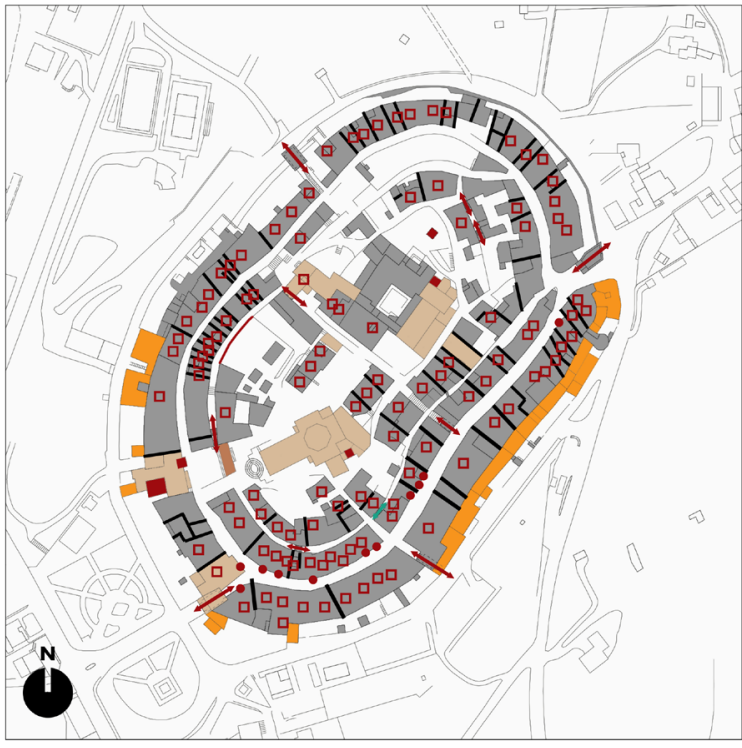

LEGEND

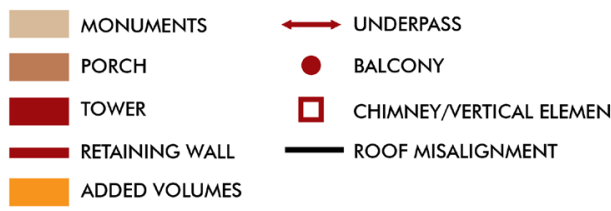

Figure 3 Historic centre of Lucignano. On the left, classification of the roads with respect to the geometrical condition $\mathrm{h} / \mathrm{w}$; on the right, map of the specific vulnerabilities of the aggregates.
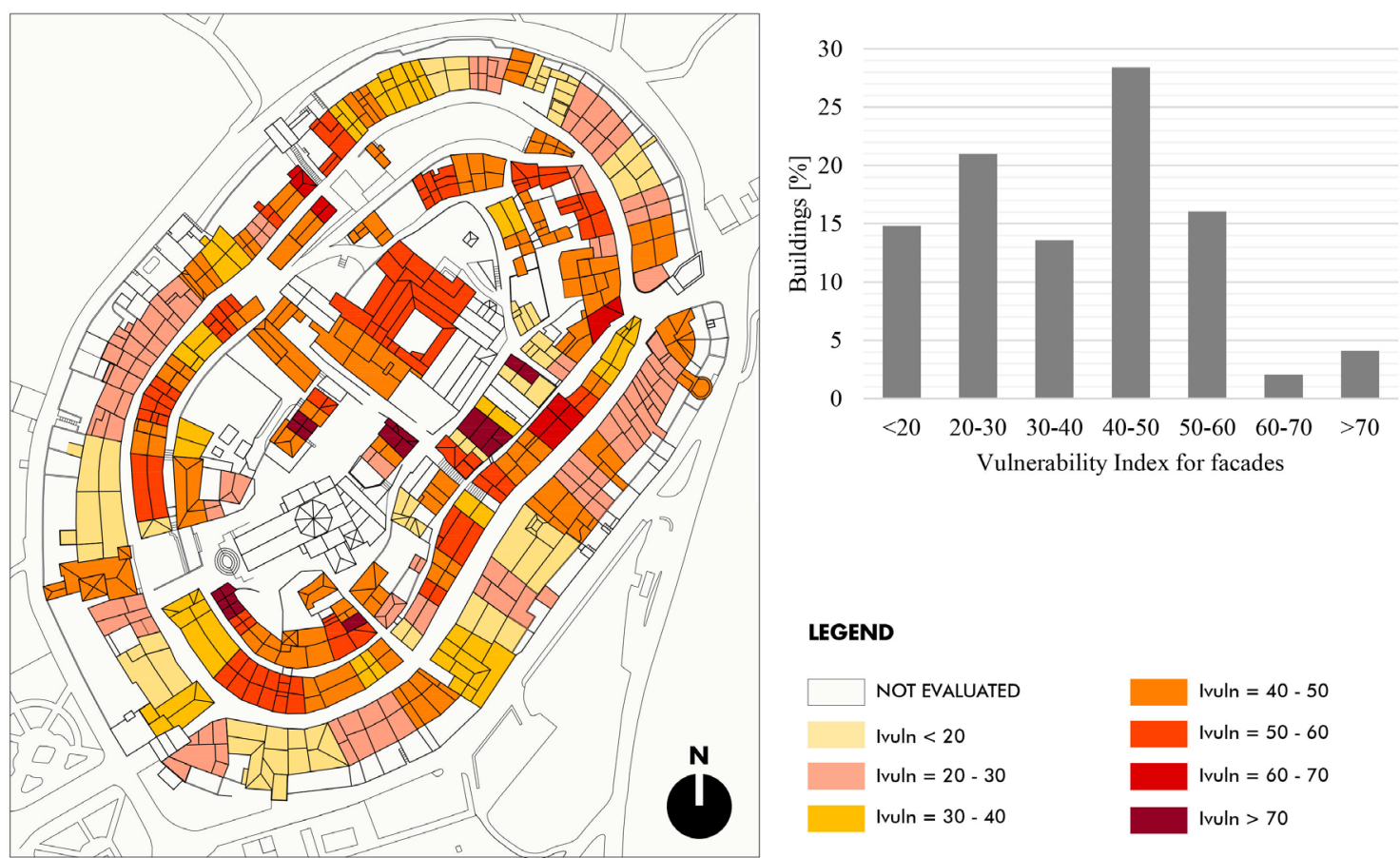

\section{LEGEND}

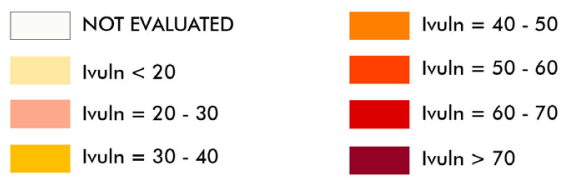

Figure 4 Vulnerability map for the historic centre of Lucignano with the histogram of the index distribution.

An important phase of the research is the evaluation of the seismic vulnerability of the buildings' facades, according to the methodology described in section 3 . The assessment regards the entire historical building stock. The index $I_{v f}$ is mapped in figure 5, which also 
summarizes its distribution in seven classes. Almost the $29 \%$ of the buildings present an $I_{v f}$ value ranging from 40 to 50 , and the $75 \%$ of them presents an index lower than 45 .

In this study, the reference damage scenario has been evaluated for a macroseismic intensity equal to VII. Hence, the mean damage grade $\mu_{d}$ can be obtained considered such intensity values and assuming a ductility factor $\mathrm{Q}=2,0$. Then, the maximum values of the $\mu_{d}$ of the buildings along the segment, are combined with the indices $I_{C h, i}^{*}$, according to the procedure described in section 4 . In figure 6 the map of $\mu_{d}$ for the street network is reported on the left, while the map of the vulnerability road network $I_{s, i}^{*}$ is reported on the right.
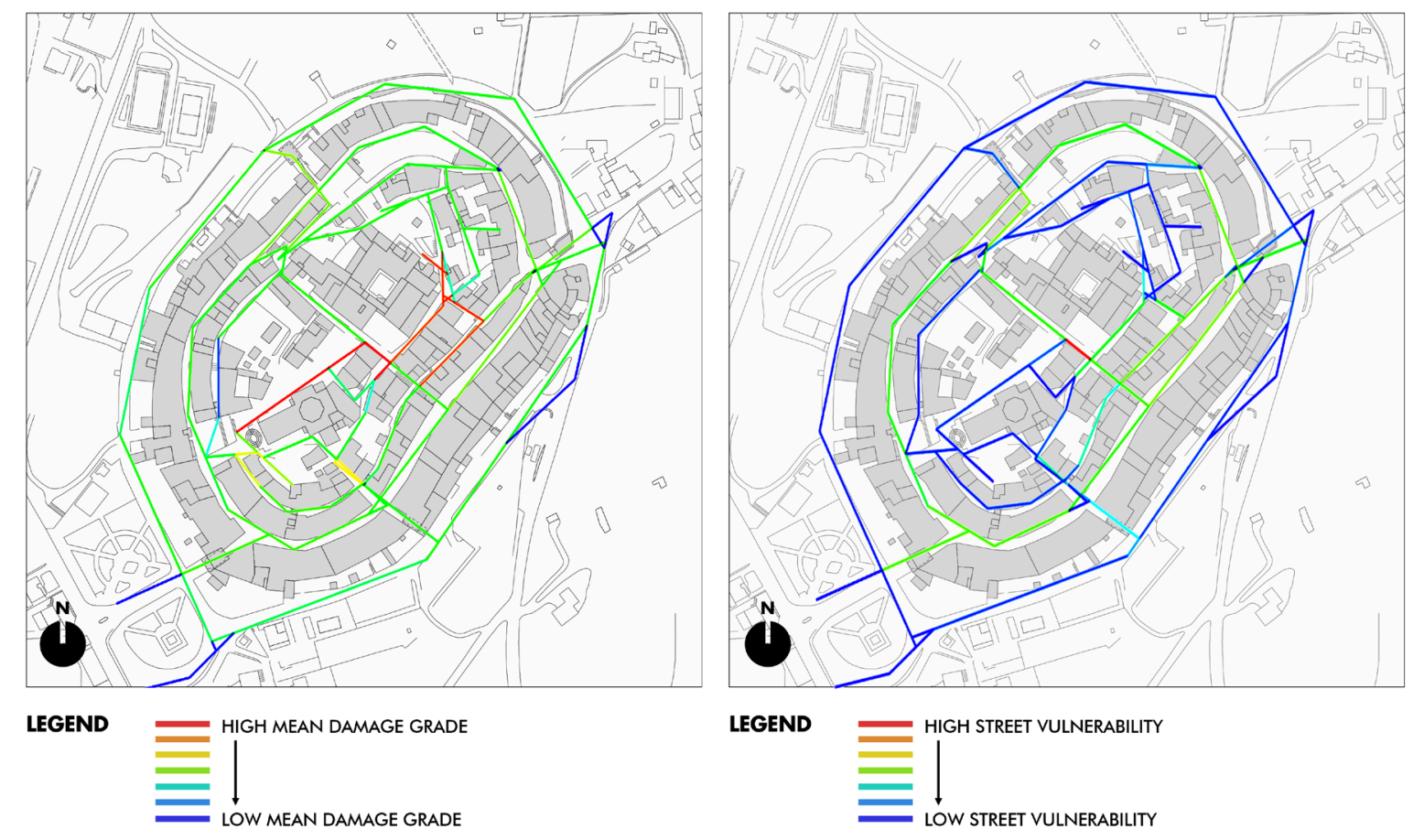

Figure 6 Historic centre of Lucignano. On the left, map of the mean damage grade $\mu_{\boldsymbol{d}}$ for each street segments; on the right, the vulnerability of the road network $I^{*}{ }_{s, i}$.

The proposed procedure allows one to take into account the importance of a street segment in the risk management process.

\section{CONCLUSIONS AND FUTURE DEVELOPMENTS}

Italian historic centres present varied urban fabrics and layouts, depending on history, orography, traditional uses, dimensions, population. In this context, critical aspects of the emergency management can be recognised in the presence of obstructions along the streets due to local or global collapses of parts of buildings along the roadside. In order to improve the emergency response of the historic centre, intervention measures can be designed on the basis of the combination of accessibility and damage scenarios.

This preliminary study introduces a procedure combining urban vulnerability analysis and configurational analysis to define a vulnerability index for the street network, taking into account the importance of each segment for the emergency management and the interference of the buildings' façade on the roadside. Proper risk mitigation actions should be adopted in order to guarantee the street safety; efforts should aim to remove vulnerabilities, reinforcing vertical elements, place restrictions on the minimum street width free of furniture and vehicles. 
This work could be used for ranking priority interventions to be included into a preventive plan.

Future developments will focus on the application of alternative empirical methodologies for the vulnerability assessment at urban scale, taking into account the local characteristics of historic centres. The proposed procedure allows one to insert other levels of information regarding for instance the height of buildings or the preferential paths of rescue teams. These effects will be evaluated in a future work.

Besides, an important step in the emergency management is the definition of the exposure of streets in this context, depending on the inhabitant density and visitors. This parameter is paramount to link the road network vulnerability to risk assessment in historic centres.

\section{REFERENCES}

[1] Jigyasu, R. Towards developing methodology for integrated risk management of cultural heritage sites and their settings. In: 15th ICOMOS General Assembly and International Symposium: 'Monuments and sites in their setting - conserving cultural heritage in changing townscapes and landscapes', 17 - 21 oct 2005, Xi'an, China.

[2] UNISDR (United Nations International Strategy for Disaster Reduction). 2015. Sendai framework for disaster risk reduction 2015-2030.

[3] Cara, S., Aprile, A., Pelà, L., Roca P. Seismic Risk Assessment and Mitigation at Emergency Limit Condition of Historical Buildings along Strategic Urban Roadways. Application to the "Antiga Esquerra de L'Eixample" Neighborhood of Barcelona, International Journal of Architectural Heritage, 2018, 12:7-8, 1055-1075.

[4] Aguado, J. L., Ferreira, T. M., \& Lourenço, P. B. The Use of a Large-Scale Seismic Vulnerability Assessment Approach for Masonry Façade Walls as an Effective Tool for Evaluating, Managing and Mitigating Seismic Risk in Historical Centers. International Journal of Architectural Heritage, 2018, 12.7-8: 1259-1275.

[5] Santarelli, S., Bernardini G., and Quagliarini E. "Earthquake building debris estimation in historic city centres: From real world data to experimental-based criteria." In: International journal of disaster risk reduction 31 (2018): 281-291.

[6] Alexander, David E. Principles of emergency planning and management. Oxford University Press on Demand, 2002.

[7] Dolce, M. The Italian national seismic prevention program. In: 15th world conference in earthquake engineering 2012, Lisbon.

[8] Bramerini F, Castenetto S. Manuale per l'analisi della Condizione Limite per l'Emergenza (CLE) dell'insediamento urbano. BetMultimedia, Rome. Italian. 2014.

[9] Galanti, E. Il Metodo Augustus, supplemento a DPCinforma. Dipartimento della Protezione Civile, Roma, 1997.

[10] Moretti M., et al. Terremoto in Emilia Romagna: le attività del Pronto Intervento Sismico durante il primo mese di emergenza. Modalità e tempistica, Quaderni Di Geofisica. $\mathrm{n}$. 110, 2013.

[11] Hillier, B., and Hanson, J. The Social Logic of Space, Cambridge University. 1984. 
[12] Hillier, B. “Cities as movement economies." Urban design international, 1996, 1.1: 4160.

[13] Hillier, B., Penn, A., Hanson, J., Grajewski, T., \& Xu, J. "Natural movement: or, configuration and attraction in urban pedestrian movement." Environment and Planning B: planning and design, 1993, 20.1: 29-66.

[14] Hillier, B., Ilda, S. Network and psychological effects in urban movement. In International Conference on Spatial Information Theory. Springer, Berlin, Heidelberg, 2005. p. 475-490.

[15] Maureira, V. M., Karimi K. A. Y. V. A. N. "The everyday and the post-disaster urban systems as one thing: A configurational approach to enhance the recovery and resilience of cities affected by tsunamis." Proceedings-11th International Space Syntax Symposium, SSS 2017. Vol. 11. Instituto Superior Técnico, Portugal, 2017.

[16] Cutini, V. "The city when it trembles. Earthquake destructions, post-earthquake reconstructions and grid configuration." 9th Space Syntax Symposium. Sejong University Press, 2013.

[17] Koch, D., Miranda Carranza, P. Syntactic resilience. In: 9th International Space Syntax Symposium, Seoul Sejong University 2013. Sejong University Press, 2013. p. 54: 1-54: 16.

[18] Emo, B, Hoelscher, C, Wiener, J., Dalton, R. Wayfinding and Spatial Configuration: evidence from street corners. In: Proceedings of the Eighth International Space Syntax Symposium. PUC, Santiago de Chile, 2012, pp. 1-16.

[19] Al-Sayed, K. Space syntax methodology. 2014. [Available online: http://discovery.ucl.ac.uk/1415080/1/Al-Sayed_SpaceSyntax-manual_2018.pdf]

[20] Dolce, M., Masi, A., Marino, M., \& Vona, M. Earthquake damage scenarios of the building stock of Potenza (Southern Italy) including site effects. Bulletin of Earthquake Engineering, 2003, 1.1: 115-140.

[21] Calvi, G. M., Pinho, R., Magenes, G., Bommer, J. J., Restrepo-Vélez, L. F., \& Crowley, H. Development of seismic vulnerability assessment methodologies over the past 30 years. ISET journal of Earthquake Technology, 2006, 43.3: 75-104.

[22] Pelà, L. New trends and challenges in large-scale and urban assessment of seismic risk in historical centres. International Journal of Architectural Heritage, 2018, 12:7-8, 10511054.

[23] Maio, R., Ferreira T. M., and Vicente R. A critical discussion on the earthquake risk mitigation of urban cultural heritage assets. International journal of disaster risk reduction, 2018, 27: 239-247.

[24] Ferreira, T. M., Vicente, R., Varum, H. Seismic vulnerability assessment of masonry facade walls: development, application and validation of a new scoring. Structural Engineering and Mechanics, 2014, 50.4: 000-000.

[25] Ferreira, T. M., Maio, R., Costa, A. A., Vicente, R. Seismic vulnerability assessment of stone masonry façade walls: Calibration using fragility-based results and observed damage. Soil Dynamics and Earthquake Engineering, 2017, 103: 21-37. 
[26] Ferreira, T. M., Maio, R., \& Vicente, R. Seismic vulnerability assessment of the old city centre of Horta, Azores: calibration and application of a seismic vulnerability index method. Bulletin of Earthquake Engineering, 2017, 15(7), 2879-2899.

[27] B. Ortolani, A. Borghini, S. Boschi, E. del Monte and A. Vignoli. Study of Vulnerability and Damage: the Case Study of Castelnuovo after L'Aquila Earthquake (Italy). In Proceedings of the 15th WCEE - World Conference of Earthquake Engineering, 2012, pp. 110, Lisbon, Portugal.

[28] Lagomarsino, S., Magenes, G. Evaluation and reduction of the vulnerability of masonry buildings. The state of earthquake engineering research in Italy: the ReLUIS-DPC, 2005, 2008: 1-50.

[29] ReLUIS, Linee guida per il rilievo, l'analisi ed il progetto di interventi di riparazione e consolidamento sismico di edifici in muratura in aggregato. 2010.

[30] Benedetti, D., Petrini, V. Sulla vulnerabilita sismica di edifici in muratura: un metodo di valutazione. A method for evaluating the seismic vulnerability of masonry buildings. L'industria delle Costruzioni, 1984, 149: 66-74.

[31] Grünthal, G. European macroseismic scale 1998. European Seismological Commission (ESC), 1998. 